\title{
DARWIN, EL PLANETA TIERRA, LAS OTRAS TIERRAS Y LOS PROFESORES DE CIENCIAS
}

\author{
Francisco Anguita Virella \\ Universidad Complutense de Madrid
}

\begin{abstract}
RESUMEN: Las conmemoraciones ofrecen oportunidades didácticas. En 2009 han coincidido las referidas a Darwin y a Galileo, que casi han solapado con la declaración de 2008 como el Año Internacional del planeta Tierra. Aparentemente heterogéneas, estas celebraciones presentan un hilo conductor común, útil para una reflexión de fondo sobre la enseñanza de la Ciencia en la Educación Secundaria.
\end{abstract}

ABSTRACT: Celebrations offer occasions for inspiring didactics. 2009 has seen the ones for Darwin and Galileo, and 2008 was declared the International Year of Planet Earth. Though apparently disparate, those three events share a common purpose, useful for an in-depth reflection on Science teaching at pre-college level.

PALABRAS CLAVE: Evolucionismo, Geología, Astronomía.

KEYWORDS: Evolution, Geology, Astronomy.

\section{INTRODUCCIÓN}

El 7 de enero de 1610, Galileo Galilei apuntó hacia Júpiter su rudimentario telescopio y observó tres de los satélites mayores del planeta. El 24 de noviembre de 1859 , se ponía a la venta (y se agotaba en pocos días) "El origen de las especies por medio de la selección natural", de Charles Robert Darwin. Y el 28 de septiembre de 2008, un grupo internacional de astrónomos publicaba sus recién obtenidas fotografías de tres planetas en órbita alrededor de la estrella HR8799, a 129 años-luz de distancia. ¿Qué tienen en común estos tres acontecimientos científicos?

Se ha señalado el descubrimiento de Galileo como el punto de partida de la revolución científica que, junto con distintos factores económicos, sociales y artísticos, impulsó el Renacimiento. En cuanto a Darwin, es un hecho no discutido que ha sido el científico que con sus ideas más ha influido en la cultura moderna. Por lo 
reciente, el último hallazgo es más difícil de calibrar; pero me arriesgo a pronosticar que abre la puerta al descubrimiento próximo de planetas semejantes al nuestro, lo que supondrá una revolución cultural al menos tan importante como las anteriores. Así pues, lo que une a estos tres hechos es su calidad de excelentes ejemplos de la repercusión social de la Ciencia. Durante los últimos siglos, y cada vez más, los trabajos de los científicos están imbricados en la sociedad: a su repercusión social se ha unido en los últimos tiempos el debate sobre la financiación de la Ciencia, y los dividendos que a cambio ésta debería devolver a la sociedad.

Los dos primeros eventos citados han merecido ser conmemorados oficialmente como el Año de Darwin (150 años de El origen de las especies y 200 de su nacimiento) y el Año Internacional de la Astronomía. Casi simultáneamente, se celebró en todo el mundo el Año Internacional del planeta Tierra. A continuación expongo algunas ideas sobre el posible aprovechamiento didáctico de este cúmulo de celebraciones.

\section{Las efemérides y las "Ciencias para el mundo contemporáneo"}

"Nuestro lugar en el Universo", "Nuestro planeta: la Tierra", "El origen de la vida" y "La revolución genética" son los títulos de los cuatro primeros temas de la recién estrenada materia de "Ciencias para el mundo contemporáneo", obligatoria en el Primer Curso de todas las modalidades del Bachillerato. Estos títulos implican a la Astronomía, la Geología y la Biología, con un nítido hilo conductor que va desde el marco más general posible (la estructura del Universo) hasta el origen del hombre. Esta asignatura está concebida como una introducción de los alumnos de Secundaria en el apasionante mundo de la ciencia moderna; y la mención al mundo contemporáneo en su título indica claramente que la intención es que en sus clases haya un intenso componente sociológico. Por ello, y a pesar de que el número de horas semanales dedicadas a la asignatura (variable según las comunidades autónomas) sea escaso, creo que merece la pena dedicar un tiempo a debatir sobre los avances científicos y su repercusión en el medio social. En esta intención, resulta una muy afortunada casualidad que tanto los avances de Galileo como los de Darwin levantasen tremendas polémicas, mayor la segunda en razón de la existencia en el siglo XIX de grandes universidades que actuaron como cajas de resonancia de las discusiones entre científicos. Algunas sugerencias para estos debates:

- Galileo y la Iglesia católica. ¿Por qué hoy nos resulta extraño que un hallazgo científico sea juzgado desde un punto de vista teológico? Lectura de párrafos seleccionados de "Vida de Galileo" de Bertolt Brecht.

- Los seguidores de Darwin. ¿Por qué los estudiantes universitarios ingleses se mostraron masivamente partidarios de las ideas evolucionistas? ¿Por qué las discusiones públicas se celebraron en un ambiente apasionado? ¿No era una simple teoría científica? ¿Por qué el propio Darwin no participó en ellas? ¿No debe un científico defender sus ideas? 
- ¿Qué importancia social puede tener el descubrimiento de planetas a decenas de años-luz de distancia? ¿Merece la pena invertir dinero en algo tan abstracto cuando hay tantos problemas sin resolver en la Tierra?

Los tres hipotéticos debates permiten poner de relieve la idea básica de que la Ciencia, en el siglo XVII o ahora mismo, está profundamente imbricada en la sociedad; por ello no es neutral, aunque a veces lo parezca. Tanto Galileo como Darwin chocaron con las ideas religiosas de su época, que surgían de lecturas literales de la Biblia, un libro poco adecuado para explicar el mundo, compuesto como está por una serie de leyendas míticas como las que han surgido en todas las sociedades primitivas. En cuanto al tercer debate, se plantea en un plano totalmente distinto: la elección de prioridades en un mundo problemático que ha caído en la cuenta de que los recursos no son inagotables. Es una discusión clásica, que enfrenta a la ciencia básica con necesidades sociales (como la lucha contra la pobreza) o bien con ciencias aplicadas, como la Medicina. Ha habido sociedades modernas que han proscrito la ciencia básica: en los países del socialismo real (1945-1989) los tribunales que juzgaban las tesis doctorales incluían obreros que tenían que decidir sobre la aplicabilidad de lo investigado; pero esa persecución de la ciencia teórica no sirvió para promover la aplicada, como quedó de relieve en la necesidad de esos países de recurrir al espionaje industrial para poder fabricar artículos de consumo.

\section{DARWIN Y LOS GEÓlOGOS}

Charles Darwin percibió claramente que para plantear su teoría sobre la aparición de especies tenía que aprender geología. Su profesor, y sin embargo amigo, fue ni más ni menos que el fundador de esta ciencia, el escocés Charles Lyell (17971875), que en 1830 había comenzado a publicar su obra "Principles of Geology". Lyell fue muy crítico con las ideas de Darwin, que encajaban mal en su idea de una Tierra esencialmente inmutable (Uniformitarismo); sólo en la $12^{\underline{a}}$ y última edición de su obra, publicada póstumamente, incluyó las ideas de su discípulo naturalista.

Esta actitud negativa de los geólogos hacia Darwin no terminó con Lyell. Encontramos un buen ejemplo en el artículo "Darwin's three mistakes" de K. J. Hsü, publicado en 1986. En él, este científico de origen chino acusa al naturalista de Shrewsbury de: (a) no detectar la existencia de extinciones masivas, (b) atribuir las extinciones de relevo exclusivamente a causas bióticas, como epidemias, y (c) como consecuencia de la primera, suponer que la vida se diversificaría cada vez más a lo largo del tiempo, sin retroceder nunca. Como vemos en la Figura 1, la biosfera ha sufrido importantes retrocesos en su diversidad, que ahora reconocemos como extinciones masivas. Sin embargo, en su conjunto no parece ésta una crítica justa: por popular que hoy sea, aún hoy hay paleontólogos (como Hoffman, 1989) que niegan el concepto mismo de extinción masiva, por lo que acusar a Darwin de no haberlo advertido, teniendo en cuenta lo incompleto del registro fósil en su tiempo, parece excesivo. Tampoco se sabía casi nada de cambios climáticos (sólo en 1837 Louis Agassiz había propuesto que el hielo había cubierto Centroeuropa) y no digamos nada de colisiones de asteroides, así que parece lógico que Darwin propusiese causas biológicas para la extinción de las especies. 


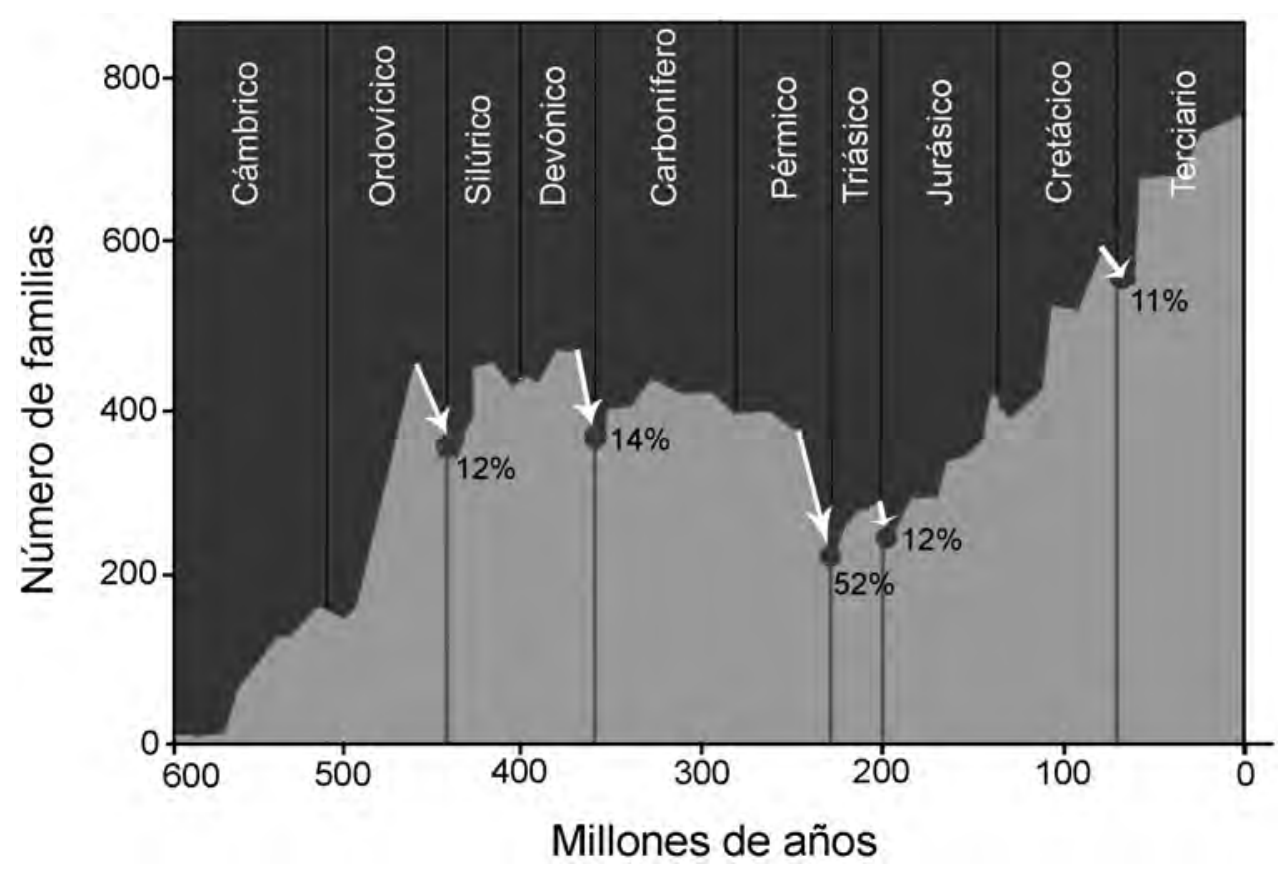

Figura 1. Desarrollo de la vida y extinciones a lo largo de la historia de la Tierra.

Resulta ilustrativo comparar las biografías de Darwin, el padre de la biología moderna, y Alfred Wegener, el fundador de la nueva geología (Anguita, 1982). Frente al viaje único del inglés, el meteorólogo alemán participó en tres expediciones a Groenlandia; y frente al retiro de Darwin a su casa solariega para estudiar las muestras recogidas en su viaje, Wegener se dedicó a la docencia universitaria, siendo, según hacen constar sus biógrafos, un profesor muy querido por sus alumnos, y un innovador en didáctica, ya que ilustraba con diapositivas sus clases de Meteorología, algo insólito en su tiempo. Esta comparación de perfiles vitales resalta el carácter tímido de Darwin, que por ello requirió defensores públicos como Thomas Huxley; a su lado, Wegener, probablemente no mucho menos tímido, sí se arriesgó a debatir en público sus ideas (con los geólogos norteamericanos) al menos una vez, en 1922 . Aquí es también pertinente una reflexión sobre la evolución social de la Ciencia entre los siglos XIX y XX: mientras que Darwin era el científico del Beagle, las expediciones en las que participó Wegener estaban compuestas por multitud de científicos, especialistas con tareas muy definidas. En cuanto al método, las diferencias son también manifiestas: Darwin es un inductivista: recopila datos, reflexiona sobre ellos, construye su teoría. Por el contrario, Wegener tiene una intuición y se enfrenta a la Naturaleza para obtener pruebas demostrativas: el método hipotético-deductivo tal como viene en los libros. Creo que la comparación va más allá de la anécdota: la forma de hacer Ciencia está cambiando, y mientras que los gentlemen naturalistas consideraban impropio interrogar a la Naturaleza con una idea preconcebida, los 
especialistas de la generación siguiente (Wegener nace dos años antes de la muerte de Darwin) empiezan a considerarlo, como se hace hoy, el método normal de trabajo; en esa época de transición, los geólogos norteamericanos acusaron a Wegener de actuar como un abogado parcial, anotando sólo los datos favorables a su teoría.

Ésta fue una más entre la lluvia de críticas que recibió en la década de 1920 la teoría del desplazamiento de los continentes. Con la perspectiva actual, ¿se puede justificar esta dura oposición? ¿Podemos calificarla de ideológica como la que atacó las ideas evolucionistas? La tentación es responder que no, que el movilismo se enfrentaba tan solo a las ideas científicas establecidas. Sin embargo, en una segunda reflexión, cabría pensar si ese rechazo frontal de la profesión geológica casi al completo a unas ideas revolucionarias no estaba tan impregnado de espíritu reaccionario como las posturas de los cardenales católicos que condenaron las ideas de Galileo, o los obispos anglicanos que combatieron el evolucionismo. A mi juicio, los factores extracientíficos (nacionalismo, acusaciones de intrusismo) pesaron mucho en el rechazo oficial de las ideas del meteorólogo alemán.

Se ha dicho que Darwin hubiese amado la tectónica de placas, que con su barajar incesante de la geografía terrestre le habría proporcionado los estímulos evolutivos óptimos para la aparición de nuevas especies. La evolución de la biosfera es inseparable de la evolución del planeta, y una de sus partes cruciales. A su vez, como Darwin intuyó, comprender la historia de la Tierra es decisivo para poder situar la evolución: las dos disciplinas se siguen necesitando como cuando eran una sola.

\section{El AÑo Internacional del planeta Tierra}

El 22 de diciembre de 2005 la Asamblea General de la ONU votó declarar el año 2008 Año Internacional del planeta Tierra (AIPT). La UNESCO, que se encargó de la organización, definió para esta conmemoración diez grandes temas: la mitad trataban de sistemas terrestres (Océanos, Aguas subterráneas, Suelos, Tierra y vida y Tierra profunda), y los otros cinco de temas medioambientales (Peligros naturales, Tierra y salud, Clima, Recursos naturales y Megaciudades). En realidad, y exceptuando el estudio de la Tierra profunda, es difícil escapar del enfoque medioambiental: ¿Cómo hablar (al gran público, o en un aula) de los mares, del agua subterránea, del suelo o de la biosfera, sin referirse a sus desequilibrios y a los riesgos que amenazan a estos sistemas? Creo que esta lista es un buen test para calibrar hasta qué punto la Geología de los tiempos de Darwin o Wegener se ha convertido inevitablemente en unas "Ciencias de la Tierra y medioambientales"; lo cual, de paso, haría justicia al Ministerio de Educación y Ciencia cuando, en los años 90, decidió sustituir aquella asignatura por ésta.

El abanico temático del AIPT es tan completo que pasar revista a las novedades en cada uno de los temas requeriría un tratado sobre la Tierra: revisaré sólo algunos aspectos que pueden dar más juego en el aula. Éstos son Tierra profunda, Clima, Peligros naturales y Recursos naturales. Mi justificación: la dinámica terrestre (que se origina en el interior del planeta) y el clima son las dos causas tanto de que éste sea un planeta peligroso como de que incluya recursos apreciados por la civilización actual. 
Por lo tanto, estos cuatro temas incluyen las dos grandes causas y las dos consecuencias mayores de las grandes preocupaciones actuales sobre el planeta.

\section{La Tierra profunda}

¿Qué tienen en común el petróleo generado en el Cretácico, el tsunami de Navidad de 2004 y las glaciaciones que cubrieron de hielo la Tierra entre 800 y 600 millones de años? Estos heterogéneos acontecimientos son expresiones de la energía interna del planeta que influyen de forma muy diversa en su superficie a través de movimientos del manto. El petróleo cretácico se acumuló a favor de un gran penacho térmico y de una paleogeografía favorable; el tsunami fue provocado por el movimiento de una falla que Ilevaba demasiado tiempo acumulando tensión; y las glaciaciones de la Tierra Blanca resultaron, se cree, de una confluencia de la mayor parte de los continentes en posiciones ecuatoriales.

Estos ejemplos nos hablan de la influencia de la Tierra profunda sobre la superficie: lo contrario sería sorprendente. Pero es que además, después de la revolución postwegeneriana, las novedades se han seguido acumulando en este campo: son por ejemplo las avalanchas en el manto y su probable influencia en la génesis de los penachos térmicos (Figura 2), o la aparente demostración de que la tectónica de placas se remonta a casi 4.000 millones de años o la iniciación precoz de una zona de subducción frente a las costas portuguesas.

\section{Temperature}

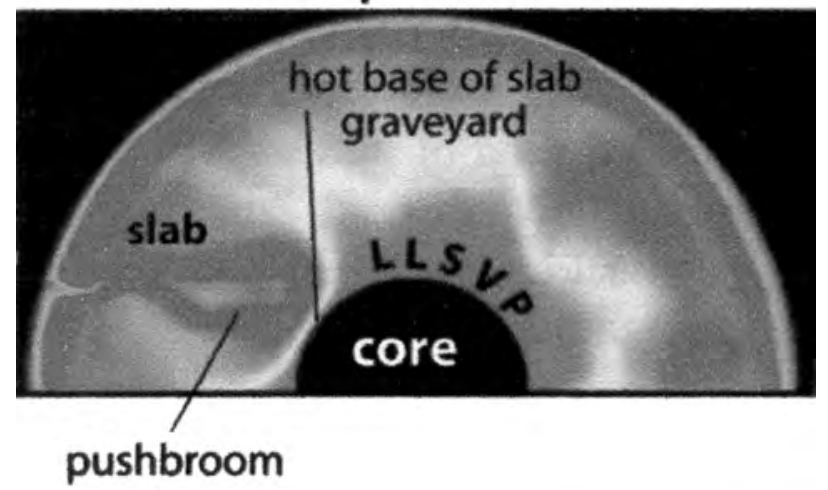

Figura 2. Un modelo del desplazamiento causado en la base del manto por litosfera subducida. En Burke et al. (2008).

\section{El clima}

El citado grupo de glaciaciones sucedidas al final del Proterozoico y que han recibido, por su extensión, el apelativo de glaciaciones de la Tierra Blanca son un caso modélico de confluencia de factores internos y externos para producir un clima singular. La paleogeografía de esta época coloca a la mayoría de los continentes en posiciones cercanas al ecuador. El exceso de lluvia habría causado la intensificación de los procesos de meteorización, que secuestran $\mathrm{CO}_{2}$, y con ello una reducción del efecto invernadero, dando paso a la glaciación. El hecho de que, a pesar de su datación relativamente reciente (en un calendario de un año, el período entre 800 y 600 
millones de años equivale a la primera quincena de noviembre) esta glaciación no se descubriese hasta 2000 (Hoffman y Schrag, 2000) nos da una idea de lo mucho que nos queda por aprender sobre la historia climática del planeta.

Esta historia está tomando en los últimos años un carácter dramático, al acumularse los indicios (Kaufman, 2009) de un deshielo acelerado, respuesta al calentamiento global causado por el aumento en la atmósfera de gases de efecto invernadero producto de la actividad industrial. A partir de ahora será difícil hablar del clima terrestre como un tema puramente científico.

\section{Peligros naturales}

Esta inestabilidad climática tiene su reflejo en una mayor turbulencia atmosférica, y con ella en un aumento de los huracanes. El que azotó a Nueva Orleáns en 2005 (Figura 3) constituyó, a pesar de ser sólo el tercero en magnitud de la temporada, el mayor desastre natural de la historia de Estados Unidos. En cuanto al tsunami que a finales de 2004 barrió las costas del Índico (Figura 4), fue causado por el movimiento de una falla frente a la costa de Sumatra. La vibración, que duró 10 minutos (un récord en la Sismología moderna), tuvo un momento sísmico Mw de 9,2, el segundo mayor desde que hay sismógrafos, y causó 230.000 muertes, la novena catástrofe en cuanto a pérdida de vidas de la historia moderna.

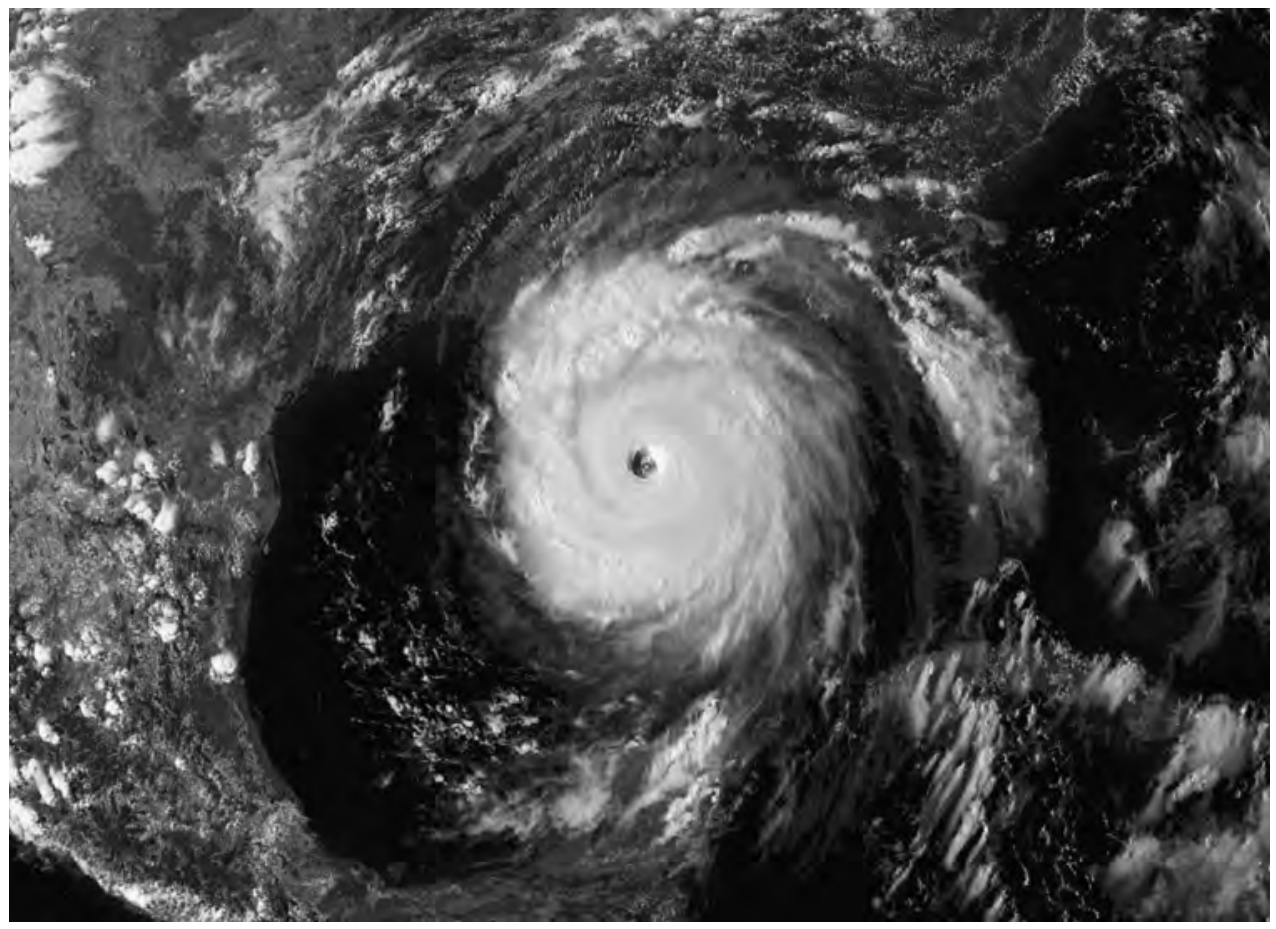

Figura 3. El huracán Katrina el 29 de agosto de 2005, a punto de tocar tierra en el sur de EE.UU. 


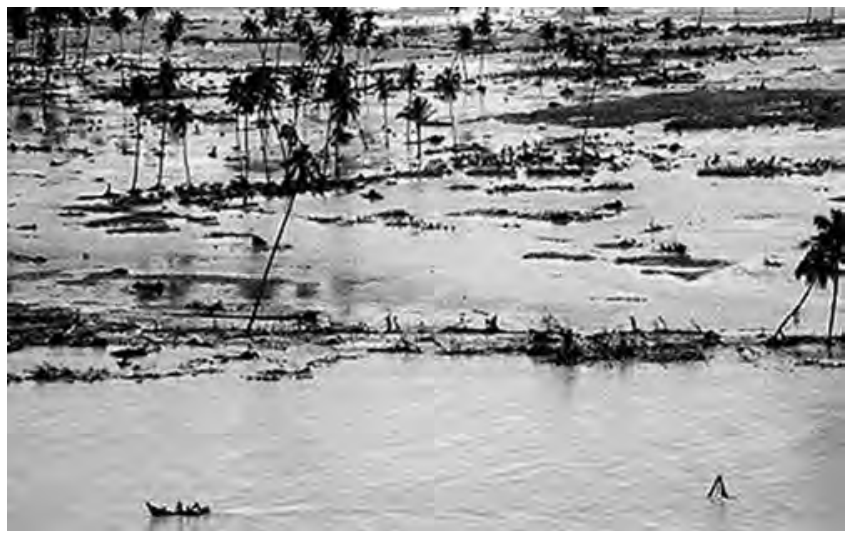

Figura 4. Devastación en una costa de Indonesia, tras el tsunami del 26 de diciembre de 2004.

¿Es la Tierra más peligrosa últimamente? Sólo en cierto sentido. Algunos de estos récords trágicos, como la frecuencia e intensidad de los huracanes, provienen de nuestra acción sobre el medio ambiente. Otros no son ahora más intensos que hace un millón de años; pero su capacidad destructiva guarda una proporción directa con nuestra ocupación intensiva de territorios que estaban ya ocupados por desastres naturales: son las rutas de los huracanes tropicales, las laderas inestables en climas Iluviosos, o las costas subductivas. Lugares a evitar, si una humanidad que marcha deprisa hacia los 7.000 millones de personas pudiese permitirse el lujo de dejar vacíos los espacios peligrosos.

\section{Recursos naturales}

El debate sobre la duración de las reservas de petróleo sigue a pleno rendimiento, a medida que las fechas anunciadas para el comienzo de su declive ( 2015 ? ¿2060?) se acercan. Los pesimistas sugieren que los historiadores futuros podrían preguntarse cómo la civilización del siglo XX pudo apostar tan fuerte por un recurso próximo a desaparecer (Figura 5), mientras que los optimistas (p. ej., Maugeri, 2009) se basan en que aún quedan gran cantidad de cuencas sedimentarias sin explorar. Alguna de ellas implica reivindicaciones territoriales que dependen, y esto cierra el círculo... de la tectónica de placas (Figura 6).

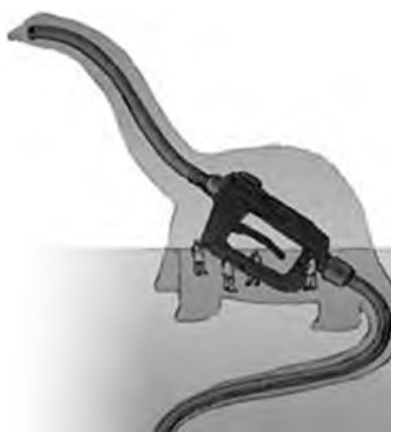

Figura 5. También los dinosaurios creían que el Cretácico no se acabaría nunca... 


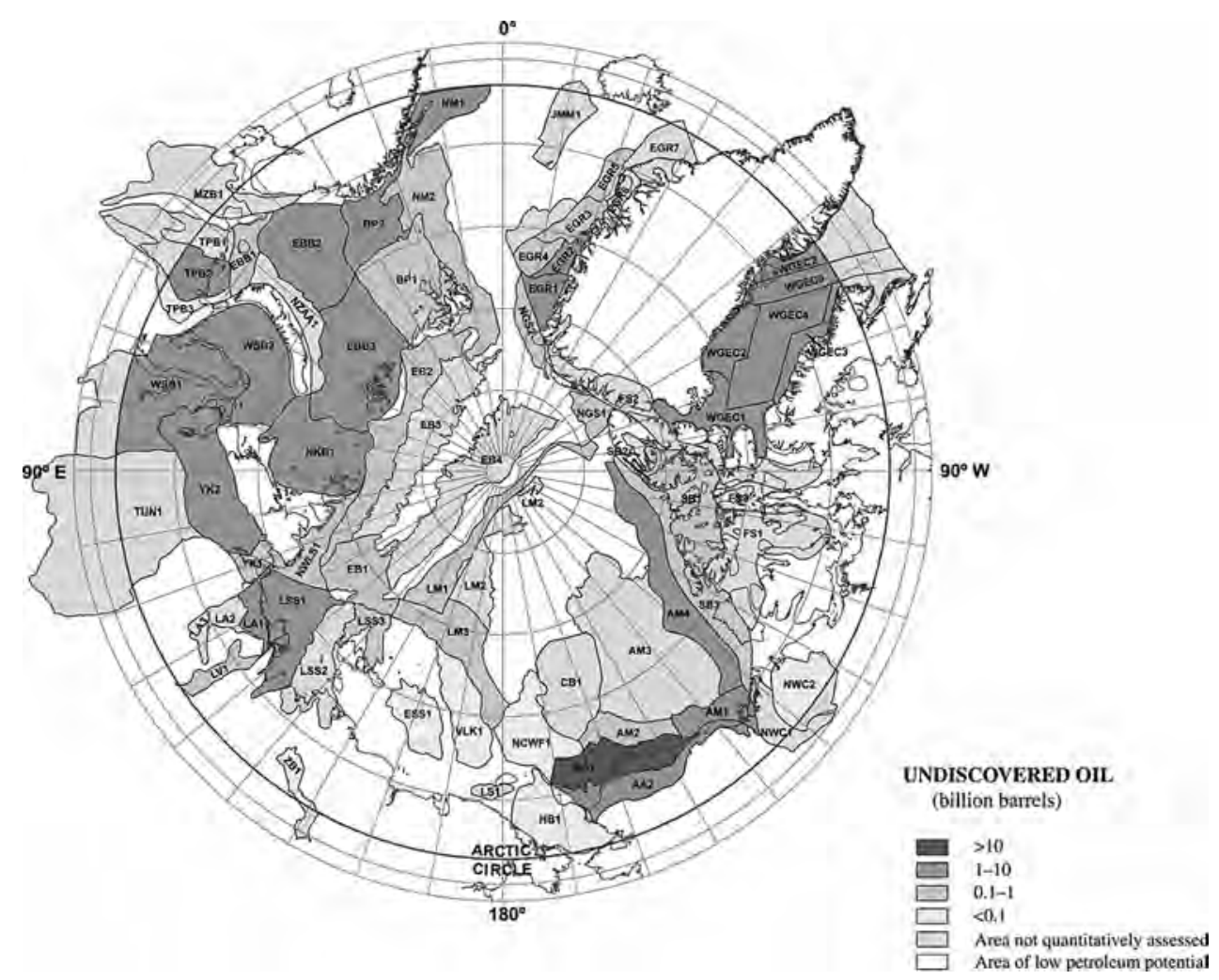

Figura 6. Las zonas del Océano Ártico que podrían contener hidrocarburos (gris intenso, $>10.000 \cdot 10^{6}$ de barriles; menos intenso, 1.000 a $10.000 \cdot 10^{6}$ barriles). El relieve que pasa por el polo norte es la dorsal de Lomonosov, cuyo origen marino o continental será clave para decidir el país al que pertenecen los hidrocarburos. En Gautier et al. (2009).

\section{DARWIN y LA ASTRONOMÍA}

Volvemos a nuestro principal homenajeado en 2009. ¿Qué relación puede guardar Darwin con la Astronomía? Esta relación existe, y se Ilama Exobiología, la búsqueda, todavía incipiente, de vida más allá de la Tierra. Los tímidos avances teóricos que comienzan a ver la luz son claramente darvinistas: una evolución propulsada por la variación genética y modulada por el ambiente (Figura 7). Nuevas perspectivas, como la terraformación de otros planetas, son por el contrario propuestas claramente antidarvinistas, en cuanto que no se basan en la adaptación de los seres vivos a los cambios ambientales sino en la modificación del medio ambiente para adaptarlo a las necesidades fisiológicas de nuestra especie. Nadie sabe si estas propuestas son técnicamente viables, pero su mero enunciado provoca un saludable temor, dado el pésimo comportamiento de nuestra especie en el cuidado de este planeta desde que lleva habitándolo. 


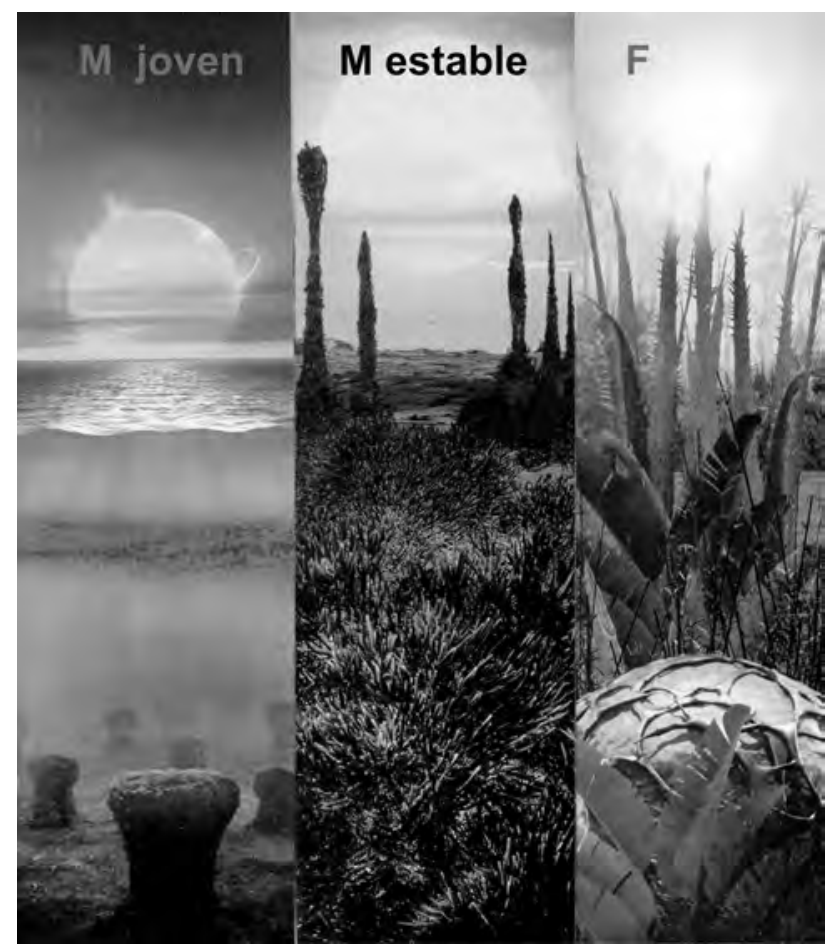

Figura 7. Paisajes de otros planetas con supuestas plantas alienígenas. Las estrellas M son de baja temperatura: cuando jóvenes emiten intensas radiaciones UV, por lo que la hipotética vida tendría que refugiarse bajo el agua. Después, las plantas que colonicen tierra firme tendrían colores oscuros para aprovechar la débil radiación. Las de tipo $F$, en cambio, son estrellas blancas más luminosas que el Sol: un color posible para sus hipotéticas plantas sería el azul, que rechazaría buena parte de la radiación. Estas suposiciones aplican la teoría darvinista de mutación-selección. En Kiang (2008).

\section{La enseñanza de la Ciencia en la Educación Secundaria}

En 2008, la Comisaría Europea de Ciencia e Investigación llevó a cabo una encuesta a 25.000 jóvenes (entre 15 y 25 años) de países de la Europa comunitaria. En ella se inquiría por sus sentimientos respecto a la Ciencia y la Tecnología. El 67\% dijo estar interesado en las noticias de estas áreas, un porcentaje igual al de los interesados en los deportes ( $i i$ !!!). Los temas-estrella (90\% de interesados) fueron la Tierra y el medio ambiente, y los nuevos inventos y tecnologías; en segundo lugar $(67 \%)$, el Universo. Un dato adicional alentador es que el $75 \%$ de los encuestados creían que la investigación estaba demasiado orientada a la obtención de beneficios, y defendían la ciencia básica. Hasta aquí, la buena noticia: la mala es que, a pesar de este elevado interés, son muy pocos los jóvenes europeos que planean dedicarse a la Ciencia: $13 \%$ a Biología y Medicina, 10\% a Ciencias Naturales y $8 \%$ a Matemáticas. En contraste, un 19\% pensaba estudiar Ciencias Sociales.

La situación parece la del típico “¿Que inventen ellos!”. ¿Puede el sistema educativo hacer algo para remediarla? Sin duda, aunque ello requerirá un serio esfuerzo de la sociedad, si es que ésta quiere seguir contando con científicos que resuelvan sus problemas. Una iniciativa interesante es la del Laboratorio Europeo para la Enseñanza de las Ciencias de la Vida (Willingale-Theune et al., 2009), donde se forma a profesores de Secundaria en prácticas de aula que aspiran a reproducir el trabajo científico real y donde también participan investigadores que visitan los 
centros dando conferencias en las que cuentan de primera mano qué significa ser científico. Pero, mientras se implantan o no desarrollos semejantes, la tarea básica del profesor de Ciencias en Secundaria seguirá siendo llevar al aula los problemas de la Ciencia actual, tanto los interrogantes sobre el mundo como los que nos permitirán mejorar nuestras vidas. Unos y otros forman parte de esa aventura maravillosa de la humanidad moderna que Ilamamos Ciencia y que surgió de las mentes de personas como Galileo Galilei, Charles Darwin o Alfred Wegener, que se atrevieron, desafiando los pensamientos únicos imperantes en sus sociedades, a buscar otras verdades, en la Naturaleza y en su imaginación.

\section{REFERENCIAS BIBLIOGRÁFICAS}

ANGUITA, F. (1982). Una comparación entre Charles Darwin y Alfred Wegener, sus actitudes científicas y la aceptación de sus teorías. II Simp. Nac. Ens. Geol., 274-287.

BURKE, K., STEINBERGER, B., TORSVIK, T. H. y SMETHURST, M. A. 2008. Plume generation zones at the margins of large low shear velocity provinces on the coremantle boundary. Earth Planet. Sci. Lett., 265, 49-60.

FURNES, H., DE WIT, M., STAUDIGEL, H., ROSING, M. y MUEHLENBACHS, K. 2007. A vestige of Earth's oldest ophiolite. Science, 315, 1704-1707.

GAUTIER, D. L. y 13 autores más. 2009. Assessment of undiscovered oil and gas in the Arctic. Science, 324, 1175-1179.

HOFFMAN, A. (1989). Mass extinctions: The view of a sceptic. J. Geol. Soc. Lond., 146, 21-35.

HOFFMAN, P. E. y SCHRAG, D. P. (2000). Snowball Earth. Sci. Am., 282-1, 50-57. HSÜ, K. J. (1986). Darwin's three mistakes. Geology, 14, 532-534.

KAUFMAN, D. S., SCHNEIDER, D. P., MCKAY, N. P., AMMANN, C. M., BRADLEY, R. S., BRIFFA, K. R., MILLER, G. H., OTTO-BLIESNER, B. L., OVERPECK, J. T., VINTHER, B. M. y ARCTIC LAKES 2K PROJECT MEMBERS (2009). Recent warming reverses long-term arctic cooling. Science, 325, 1236-1239.

KIANG, N. Y. (2008). The color of plants on other worlds. Sci. Am., 298-4, 28-35.

MAUGERI, L. (2009). Squeezing more oil from the ground. Sci. Am., 301-4, 36-43.

NEVES, M. C., TERRINHA, P., AFILHADO, A., MOULIN, M., MATIAS, L. y ROSAS, F. 2009. Response of a multi-domain continental margin to compression: Study from seismic reflection-refraction and numerical modelling in the Tagus Abyssal Plain. Tectonophysics, 468, 113-130.

WILLINGALE-THEUNE, J., MANAIA, A., GEBHARDT, P., DE LORENZI, R. y HAURY, M. (2009). Introducing modern Science into schools. Science, 325, 1077-1078. 